\title{
Correlation Between Posterior Tibialis Tendon Dysfunction with Ultrasonography and Adult Acquired Flatfoot Deformity with Radiographic X-ray and Feiss line in East Java's Indonesian Professional Athletes
}

Rosy Setiawati ( $\square$ rosy-s@fk.unair.ac.id)

Universitas Airlangga Fakultas Kedokteran https://orcid.org/0000-0001-8442-7287

Alfian Hasbi

Universitas Airlangga Fakultas Kedokteran

Paulus Rahardjo

Universitas Airlangga Fakultas Kedokteran

Damayanti Tinduh

Universitas Airlangga Fakultas Kedokteran

Alit Pawana

Universitas Airlangga Fakultas Kedokteran

Giuseppe Guglielmi

Foggia University Hospital: Azienda Ospedaliera Universitaria Foggia

Original Research Article

Keywords: Posterior tibialis tendon dysfunction, Adult acquired flatfoot deformity, ultrasound, radiographic x-ray, tenosynovitis, tear

Posted Date: April 8th, 2021

DOI: https://doi.org/10.21203/rs.3.rs-324924/v1

License: (c) (i) This work is licensed under a Creative Commons Attribution 4.0 International License.

Read Full License 


\section{Abstract}

Background : Adult acquired flatfoot deformity (AAFD) is marked with a partial or complete flattening of the longitudinal medial arch that developed after maturity. AAFD, secondary to posterior tibialis tendon dysfunction (PTTD), is one of the most frequent foot and ankle pathologies in professional athletes. Different modality and procedures can be used to establish the diagnosis of AAFD and PTTD However, the correlation of these various clinical and imaging measurements with specific injuries of the PTT and supporting medial longitudinal arch structures has not been fully reported. The purpose of this study is to investigate the correlation between PTTD using ultrasonography and AAFD that diagnosed using both radiographic $x$-ray and feiss line examination.

Method : 112 professional athletes with flat foot deformity on physical examination, symptom of PTT dysfunction such as medial ankle or foot pain, focal pain along the course of the PTT underwent foot radiographic $x$-ray using calcaneal inclination angle, ankle ultrasound to see PTT abnormality and feiss line examination using three degree of flat foot classification.

Result : There were strong association between calcaneal inclination angle and PTTD includes the presence of PT tendon sheath fluid as well as tendon sheath thickening with $\mathrm{p}<0.05$ with correlation coefficient $(r)=0.921$ and 0.892 respectively. Weak association were also found between feiss line result and PT tendon sheath fluid as well as tendon sheath thickening with correlation coefficient $(r)=$ 0.288 and 0.244 . There were non significant association between calcaneal inclination and partial PT tendon tear as well as calcaneal inclination and feiss line result.

Conclusion : A compressive understanding of posterior tibialis tendon dysfunction and flatfoot diagnosis will lead to more effective management in reducing the symptom.

\section{Introduction}

The foot of human has become exceptionally specialized for the performance of two divergent functionsstatic balance \& propulsion. Various arches were the main features to make the series of bones forming to do the balance \& propulsion. Flat foot occurs from a partial or complete collapse of the arch Propulsion and static balance were the main functions in human foot that made them unique. ${ }^{1}$ Flatfoot cause several complications such as foot pain, knee pain, back pain and postural disturbance. ${ }^{2}$ These pains rarely occur on babies and children, but the main cause of pain on runners and increase the risk of sport injury Adult Acquired Flatfoot Deformity may cause some symptoms and complications such as postural disturbance, knee pain and foot pain, all of them were the most common cause of pain on professional athletes in sport injury. ${ }^{3}$ Adult acquired flatfoot deformity (AAFD) is marked with a partial or complete flattening of the longitudinal medial arch that developed after maturity. ${ }^{4}$ AAFD, secondary to posterior tibialis tendon dysfunction (PTTD), is one of the most frequent foot and ankle pathologies in professional athletes and also approximately 5 million adults in America. ${ }^{5}$ The disorder is initiated most commonly by dysfunction of the posterior tibialis tendon (PTT), which normally functions to maintain the 
talonavicular joint at the apex of the three arches of the foot. There are several causes of AAFD, such as PTTD, trauma, neuroathropathy, neuromuscular disease, inflamamatory arthritis and the most common is PTTD. 4 ; 6

The overuse injury in professional athletes with AAFD is one of the cause of PTT degeneration. ${ }^{7 ; 8}$ PTT degeneration encompasses tenosynovitis, tendinosis, tendon elongation, and tendon tearing. The malaligned foot is initially flexible but becomes rigid and constant as the disorder progresses. ${ }^{4}$

Different modality and procedures can be used to establish the diagnosis of AAFD and PTTD such as clinical diagnosis as well as imaging diagnosis include radiographic $\mathrm{x}$-ray, ultrasound and MRI. ${ }^{9}$ The gold standard for the evaluation of adult acquired flatfoot is weight-bearing radiographs. Radiographs are necessary in the anteroposterior, lateral, and hindfoot views. These views will assess the degree of arch collapse, particularly by measuring the calcaneal inclination and lateral first tarsometatarsal angle. ${ }^{10 ; 11}$ Several studies indicate that ultrasound may be a useful modality in assessing the posterior tibial tendon when compared to the more time consuming and costly MRI. Results from an ultrasonographic evaluation of the posterior tibial tendon were equivalent to MRI in $87 \%$ to $94 \%$ of patients. ${ }^{11 ; 12}$

However, correlation of these various clinical and imaging measurements with specific injuries of the PTT and supporting medial longitudinal arch structures has not been fully reported. Multimodality evaluation using radiographic $x$-ray, ultrasonography and feiss line examination in professional athletes that examine the correlation between PTTD and AAFD has not been widely studied yet. Through this study, sports science can be applied in the process of seeding athletes since a comprehensive approaches include promotion, preventative, curative as well as rehabilitative management will enhance the long-term athletic performance. The aims of this study was to investigate the correlation between PTTD using ultrasonography and AAFD that diagnosed using both radiographic x-ray and feiss line examination.

\section{Method}

\subsection{Subjects}

Approval from institiuional review board from Ethics Committee of Soetomo General Academic Hospital, Surabaya (2043/118/KEPK/III/2020) had been obtained. The inclusion sample consisted of 112 athletes with flat foot deformity on physical examination, symptom of PTT dysfunction such as medial ankle or foot pain, focal pain along the course of the PTT who underwent ankle ultrasound, radiographic x-ray, and feiss line examination in Sport Clinic of Soetomo General Academic Hospital Surabaya on March 2020. Athlete who had history of ankle or pedis trauma, previous intensive treatment for flatfoot were excluded from the sample.

This study is an observational analytic using a cross-sectional study design that assesses the correlation of the thickness of the fluid around the PTT, the thickness of the PTT tendon sheath, the degree of fluid 
area around the PTT, and the tearing of the PTT were diagnosed from the ultrasound with the calcaneal inclination angle of the radiographic x-ray lateral pedis as well as feiss line examination.

\subsection{Radiography $x$-ray and Ultrasonography}

Weight-bearing radiography $\mathrm{x}$-rays of the foot and ankle lateral projection remained the gold standard for the diagnosis of adult-acquired flatfoot deformity. ${ }^{11 ; 13}$ X-ray machine unit of DRGEM Stationary X-ray System GXR-C52SD was used for examination. Standing anterosuperior (AP) and lateral views of the foot were obtained for athletes (Figure.1). All radiographs were obtained in a weight-bearing position with standardized technique using the same digital radiography system. The digital $\mathrm{x}$-ray detector (film) and the x-ray tube (source) are 35-40 inchies apart in both the AP and lateral views of foot. When the AP view of the foot is taken, the xray tube source was angled at $10^{\circ}$. Calcaneal inclination angle is one of the most common measurement to make the diagnosis for flatfoot deformity (Figure.2). ${ }^{4}$ The calcaneal inclination angle was measured by the angle between the line that paralells to plantar calcaneal surface and the horizontal plane. Alignment angle (degrees) $<18^{\circ}$ is categorized as pes planus. Schematic anatomy of posterior tibial tendon is seen in Figure 3.

The PTT is well assessed with US. We used GE Logiq P9 ultrasound machine in scanning of the PTT. Tranducer positioning of posterior tibialis tendon for ultrasound scanning is very important so we can get the correct results. It is scanned in both longitudinal and transverse position (Figure 4). Posterior tibialis dysfunction appeared as tenosynovitis, tear or tendinosis. Free fluid collection that made hypoechoic lesion around posterior tibialis tendon and a sheath size of greater than $7 \mathrm{~mm}$ was tenosynovitis (hyperechoic central structure with a hypoechoic halo) on the ultrasound transverse position. Posterior tibialis tendon tear or rupture appeared from ultrasound as an empty tibial groove and have a gap intermuscular of posterior tibialis tendon. Tendinosis results in thickening, with heterogeneous hypoechoic regions replacing the normal fibrillar architecture. ${ }^{4 ; 10 ; 15}$ All of the radiograph measurement and US examination were performed by a senior musculokeletal radiology consultant with more than 10 years of experience.

\subsection{The Feiss Line Test}

The feiss line test used to measure the degree of fall or fall of the navicular in standing. It is possible to quantify the medial longitudinal arch using a simple setup, without the need for identification of subtalar neutral position. The Feiss line is defined as an imaginary straight line from the medial malleolus through the navicular bone to the center of the head of the first metatarsal. ${ }^{17}$ Patient is asked to sit on a chair with feet on the floor. The navicular tubercle is marked while sitting, again the patient is asked to stand up, then the navicular tubercle is marked again and observe if the navicular falls while standing (Figure 7 ). If the tubercle falls $1 / 3$ of the distance to the floor, it represents a level leg of 1 degree; if it falls $2 / 3$ of the distance to the floor, it is level 2; if attached to the floor, it represents a 3 degree flatfoot. ${ }^{18}$ 
We use SPSS 24 software (IBM, Armonk, New York, United States) for statistical analysis. Data from ultrasonography, radiographic x-ray, and The Feiss Line Test were arranged in table and analyzed.

\section{Results}

In this study (Table 1), a sample of athletes from various sports with the highest number of flatfoots was obtained is wrestling (30.4\%) and the lowest number is gymnastic (3.6\%). From wrestling atheles group, we also found the highest number of PTTD (tenosynovitis and tear) and flat foot incidence of $21,4 \%$ among other sports. From all atheles, 43\% showed normal PTT ultrasound finding and $33 \%$ showed normal calcaneal inclination angles from radiograph

From ultrasound finding of this study, the size of the tendon sheath fluid thickness around the posterior tibial tendon, the thickness of the posterior tibial tendon sheath, the presence of a tear in the posterior tibial tendon as well as their correlation to the calcaneal inclination angle data from the radiographic examination and feiss line test from clinical ankle-foot examination were analyzed. We found the range of fluid thickness of the sample were $0-5.8 \mathrm{~cm}$ with a mean value of $2.57 \mathrm{~cm}$ and a median value of 2.8 $\mathrm{cm}$. The thickness of the posterior tibial tendon sheath ranges from $5.5-13 \mathrm{~cm}$ with a mean value of 8.25 $\mathrm{cm}$ and a median value of $8.2 \mathrm{~cm}$. The the posterior tibial tendon tears ranges from 0.12 to $0.27 \mathrm{~cm}$ with a mean value of $0.013 \mathrm{~cm}$. The calcaneal inclination angle from $x$-ray radiographic measurement ranges from 9.5-23.1 with a mean value of 17.2 and a median value of 16.6 (Table 2). From 112 samples we got $67 \%$ had first degree of flatfoot, $20,5 \%$ second degree, 1,5\% got third degree. Radiographic examination shows similar results approximately $70,5 \%$ were flatfoot (Table. 3 )

Based on the Kolmogorov-Smirnov distribution test, it was found that the PTT thickness was the ratio data that was normally distributed in the group of East Java's Indonesian professional athletes in, the correlation hypothesis test were carried out using the Pearson test. Based on the correlation test, there is a very strong correlation between the thickness of the fluid around the posterior tibial tendon and the calcaneal inclination angle with $p<a(p=0.000 ; a=0.05)$ and a correlation coefficient $(r)=0.921$. In the other hand, there is a weak correlation between the thickness of the fluid around the posterior tibial tendon with feiss line test with $p<a(p=0.003 ; a=0.05)$ and a correlation coefficient $(r)=0.280$. A very strong correlation is found between the thickness of the posterior tibial tendon sheath and the calcaneal inclination angle with $p<a(p=0.000 ; a=0.05)$ and a correlation coefficient $(r)=0.892$. From the correlation between posterior tibial tendon sheath thickness and feiss line test showed weak correlation with $p<a(p=0.001 ; a=0.05)$ and correlation coefficient $(r)=0.244$. Compared to the previous variables, the correlation between tibialis tendon partial tear and calcaneal inclination as well as feiss line test resulted in not significant correlation with $p<a(p=0.728 ; a=0.05)$ and a correlation coefficient $(r)=$ 0.033 for calcaneal inclination, while $p<a(p=0.541 ; a=0.05)$ with a correlation coefficient $(r)=0.058$ for feiss line test (Table.4) (Table.5) (Table.6).

\section{Discussion}


Acquired adult flatfoot is classified according to clinical symptoms, the severity of the foot deformity, and whether the deformity is flexible or fixed. ${ }^{19 ; 20}$ The foot was mainly supported by posterior tibialis tendon to maintain medial longitudinal arch and balancing the hindfoot against valgus deformity. Accordingly, adult acquired flatfoot deformity can be caused by posterior tibialis tendon dysfunction. Posterior tibialis tendon dysfunction manifestation given an overview in the form of tendinosis, tenosynovitis, and tear. When the person got posterior tibialis tendon dysfunction, the body weight distribution will be disturbed to the supporting structures, consisting of spring ligamentum complex, sinus tarsi ligament, and deltoid ligament complex. Distribution from this structure can caused flatfoot deformity. ${ }^{19}$

Classification regarding to the severity of flatfoot deformity in relation to posterior tibial tendon dysfunction was proposed by Johnson and Strom in 1989 (Wacker $\mathrm{J}$ at al., 2003). ${ }^{21}$ In athletes, the state of the foot greatly depends on the type of effort and weight of the load carried, which differs in different disciplines, and on the type of surface on which training and competition are carried out. This situation will increase the burden the the foot arch. This study showed that's the majority of athletes have flatfoot deformity and posterior tibialis tendon tenosynovitis. These results are correlated with previous studies Lichota et al that the majority of sportsmen especially in athletics have flatfoot deformity. Research on the variability of foot-arches among practitioners of different sporting has already been carried out by Nizankowski and Wanke, found that the greatest risk factor for the diagnosis of flatfoot and posterior tibial tendon dysfunction occurs in sports athletes. Author also found only very few athletes $(6,3 \%)$ that have tear at posterior tibialis tendon this have a different result from previous studies by Hsu, T.C., Wang which had $(43,75 \%)$ from total sample. ${ }^{15}$

In this study, a sample of athletes from various sports with the highest number of flatfoots was obtained is wrestling. This finding is con with previous research by Mira Saraswati Kumala with the results of the three categories with the most flatfoot deformity, include football, takraw, athletics and wrestling. The sport that has the greatest number and greatest percentage of flatfoot is wrestling. These finding were similar with previous study by Mira Saraswati Kumala with resulted in the top three largest sport that is related to flatfoot deformity including sepak takraw, athletic and wrestling. From the table no 5 and 6 concludes that characteristic of flatfoot and tenosynovitis most likely bilateral foot and only very few samples that only had unilateral flatfoot or unilateral posterior tibial tenosynovitis. Thisfindings are concordance with previous study by Mira Saraswati Kumala that only $(14,3 \%)$ have unilateral flatfoot. ${ }^{3}$

In this study, we found that there is a statistically significant association between calcaneal inclination angle with PT tendon sheath thickening and tendon sheath fluid as diagnosed on ultrasound. Our findings are supported by Karasick and Schweitzer evaluated patients with surgically proven PTT tears and found that $50 \%$ of the patients had a decreased calcaneal pitch angle and also by Lin et al that showed significant association between some radiograph measurements include calcaneal inclination angle with PTTD diagnosed on MRI. ${ }^{19 ; 22}$ On the other hand, a non signicant association is found between feiss line grading system with PT tendon sheath thickening and tendon sheath fluid. It assumes that the imaging evaluation using radiograph and ultrasound plays an important role in 
diagnosing of PTTD and AAFD to confirm the clinical assessment respectively. This is reasonable, because PTTD including tears and diffuse PT tenosynovitis can lead to tendon lengthening due to tendon fiber disruption, which will cause the medial longitudinal arch to fail and lead to abnormal radiographic measurements. However, this study also found PTTD in normal calcaneal inclinations. These findings suggest that in focal PTT tendinosis and isolated tenosynovitis, the tendon although abnormal is structurally intact; thus, the longitudinal medial curvature will be maintained and radiographic measurements will remain within normal limits. ${ }^{19}$ The angle of inclination of the calcaneals is well associated with injury to the supporting structures of the medial longitudinal arch. This is indicated by the strong relationship with PTTD found on ultrasound, this may be due to the ease in calculating this measurement. Bone landmarks used to calculate calcaneal pitch angle are often preserved even in cases of severe leg deformity. ${ }^{19}$ therefore, precise measurements can still be obtained. Ultrasound has recently become a widely used diagnostic tool for PT tendon lesions in sports injuries, due to its ability to visualize the fibers in the desired projection and real-time functional state, as well as to provide a variety of PTTD findings including tearing, tendon fiber thickening, heterogeneity. Thickening of the tendon sheath echogenicity as well as fluid of the tendon sheath. $4 ; 15 ; 25$

The limitation of the study was the amount of the sample which are only limited variety type of sports. Furthermore, there was no surgical proof since all of our patients were treated conservatively with most ultrasound finding was tendinosis, tenosynovitis as well as partial tendon tear. No tendon rupture is detected on the sample group. We only use calcaneal inclination angle as the radiograph evaluation, so that further study is better considered to perfome using multiparameter radiograph measurements.

As a summary in our study, we could confirm the statistically significant relation between PTTD found on the ultrasound in key structures for the stabilization of plantar arch. We have opinion that this study is very useful to make better analyze study to understand more about the risk factor and type of sports that tend to have more predispotition to increase the chance of being flatfoot deformity and posterior tibialis tendon dysfunction. The association between these ultrasound-diagnosed structures and signs of radiological flat foot and PTTD and its possible physiopathological mechanisms can be especially useful for a precise diagnosis to support a comprehensive management.

\section{Conclusion}

Posterior tibialis tendon plays an important role in dynamic support of arch. This study conducted that there is a close relation between posterior tibialis tendon dysfunction, flatfoot deformity in professional athletes, that posterior tibialis tendon dysfunction is common cause of acquired flatfoot deformity. A compressive understanding of posterior tibialis tendon dysfunction and flatfoot diagnosis will lead to more effective management in reducing the symptom

\section{Declaration}

Ethical Clearance 
This manuscript has been accepted by ethical clearance department Dr. Soetomo Hospital. Ethical clearance number is 1988/KEPK/V/2020.

\section{Funding}

We don't have funding or sponsor

\section{Competing interests}

Rosy Setiawati has no conflict of interest

Alfian Hasbi has no conflict of interest

Paulus Rahardjo has no conflict of interest

Damayanti Tinduh has no conflict of interest

Alit Pawana has no conflict of interest

Giuseppe Guglielmi has no conflict of interest

\section{Author Contribution}

Rosy Setiawati : Study conception and design; Analysis and interpretation of data; Drafting of manuscript; Critical revision

Alfian Hasbi $\quad$ : Study conception and design; analysis and interpretation of data

Paulus Rahardjo : Study conception and design; analysis and interpretation of data

Damayanti Tinduh : analysis and interpretation of data; drafting manuscript

Alit Pawana $\quad$ : analysis and interpretation of data; drafting manuscript

Giuseppe Guglielmi : Study conception and design; Analysis and interpretation of data; Drafting of manuscript; Critical revision

\section{Acknowledgment}

A sincere gratitude to all my teachers, colleagues, family, and all the patients included in this study.

\section{Author information}

\section{First Author and Coresponding author:}

Name : Rosy Setiawati 
Affiliation : Musculoskeletal consultant, Department of Radiology, Faculty of Medicine, Airlangga University, Surabaya

Email : Rosy-s@fk.unair.ac.id

Orcid id : https://orcid.org/0000-0001-8442-7287

\section{Second Author :}

Name $\quad$ : Alfian Hasbi

Affiliation : Radiology residency, Radiology Department, Faculty of Medicine, Universitas Airlangga, Surabaya, Indonesia

Email : alfianhasbi@gmail.com

Orcid id :

Third Author :

Name : Paulus Rahardjo

Affiliation : Musculoskeletal consultant, Department of Radiology, Faculty of Medicine, Airlangga University, Surabaya

Email : Paulus.r.rahardjo@gmail.com

Orcid id : 0000-0002-1821-4811

\section{Fourth Author :}

Name : Damayanti Tinduh

Affiliation : Consultant of Department of Physical Medicine and Rehabilitation, Faculty of Medicine, Universitas Airlangga, Surabaya, Indonesia

Email : damayanti.tinduh@fk.unair.ac.id

Orcid id :

\section{Fiveth Author :}

Name : Alit Pawana

Affiliation : Consultant of Department of Physical Medicine and Rehabilitation, Faculty of Medicine, Universitas Airlangga, Surabaya, Indonesia 
Orcid id :

\section{Seventh Author :}

Name : Giuseppe Guglielmi

Affiliation : Department of Clinical and Experimental Medicine, School of Medicine, Foggia University, Foggia, Italia; Department of Radiology, School of Medicine, Foggia University, Foggia, Italia

Email: filippo.delgrande@eoc.ch

Orcid Id : 0000-0002-4325-8330

\section{Abbreviations}

AAFD : Adult acquired flatfoot deformity (AAFD)

AP : Anterosuperior

PTT : Posterior tibialis tendon

PTTD : Posterior tibialis tendon dysfunction

\section{References}

1. Sharma J, Upadhyaya P. Effect of flat foot on the running ability of an athlete. Indian Journal of Orthopaedics Surgery. 2016;2(1):119.

2. Chen J, Chung M, Wang M. Flatfoot Prevalence and Foot Dimensions of 5- to 13-Year-Old Children in Taiwan. Foot \& Ankle International. 2009;30(4):326-332.

3. Kumala M, Tinduh D, Poerwandari D. Comparison of Lower Extremities Physical Performance on Male Young Adult Athletes with Normal Foot and Flatfoot. 2019.

4. Flores D, Mejía Gómez C, Fernández Hernando M, Davis M, Pathria M. Adult Acquired Flatfoot Deformity: Anatomy, Biomechanics, Staging, and Imaging Findings. RadioGraphics. 2019;39(5):1437-1460.

5. Goss M, Stauch C, Lewcun J, Ridenour R, King J, Juliano P et al. Natural History of 321 Flatfoot Reconstructions in Adult Acquired Flatfoot Deformity Over a 14-Year Period. Foot \& Ankle Specialist. 2020;:193864002091285.

6. Henry J, Shakked R, Ellis S. Adult-Acquired Flatfoot Deformity. Foot \& Ankle Orthopaedics. 2019;4(1):247301141882084. 
7. Chang C, Chen Y, Yang W, Ho P, Hwang A, Chen C et al. Flatfoot Diagnosis by a Unique Bimodal Distribution of Footprint Index in Children. PLoS ONE. 2014;9(12):e115808.

8. Ikpeze T, Brodell J, Chen R, Oh I. Evaluation and Treatment of Posterior Tibialis Tendon Insufficiency in the Elderly Patients. Geriatric Orthopaedic Surgery \& Rehabilitation. 2019;10:215145931882146.

9. Pita-Fern\&aacute;ndez S, Gonz\&aacute;lez-Mart\&iacute;n C, Seoane-Pillado T, L\&oacute;pezCalvi\&ntilde;o B, P\&eacute;rtega-D\&iacute;az S, Gil-Guill\&eacute;n V. Validity of Footprint Analysis to Determine Flatfoot Using Clinical Diagnosis as the Gold Standard in a Random Sample Aged 40 Years and Older. Journal of Epidemiology. 2015;25(2):148-154.

10. Hasbi A, Setiawati R, Rahardjo P, Dwi Sensusiati A. Characteristic of Posterior Tibialis Tendon Dysfunction and Adult Acquired Flatfoot Deformity in Professional Athletes. International Journal of Research Publications. 2020;60(1).

11. Arnoldner M, Gruber M, Syré S, Kristen $\mathrm{K}$, Trnka H, Kainberger $\mathrm{F}$ et al. Imaging of posterior tibial tendon dysfunction-Comparison of high-resolution ultrasound and 3T MRI. European Journal of Radiology. 2015;84(9):1777-1781.

12. Harish S, Kumbhare D, O'Neill J, Popowich T. Comparison of Sonography and Magnetic Resonance Imaging for Spring Ligament Abnormalities. Journal of Ultrasound in Medicine. 2008;27(8):11451152.

13. Abousayed M, Alley M, Shakked R, Rosenbaum A. Adult-Acquired Flatfoot Deformity. JBJS Reviews. 2017;5(8):e7.

14. Belhan $O$, Kaya M, Gurger M. The thickness of heel fat-pad in patients with plantar fasciitis. Acta Orthopaedica et Traumatologica Turcica. 2019;53(6):463-467.

15. Hsu T, Wang C, Wang T, Chiang I, Hsieh F. Ultrasonographic Examination of the Posterior Tibial Tendon. Foot \& Ankle International. 1997;18(1):34-38.

16. Lhoste-Trouilloud A. The tibialis posterior tendon. Journal of Ultrasound. 2012;15(1):2-6.

17. Spörndly-Nees, Søren et al. "The navicular position test - a reliable measure of the navicular bone position during rest and loading."International journal of sports physical therapy 6,3 (2011): 199205.

18. Prakash A, Maurya S. Relationship between degree of foot pronation and disability associated with low back pain. International Journal of Physical Education, Sports and Health. 2019;6(5).

19. Lin Y, Mhuircheartaigh J, Lamb J, Kung J, Yablon C, Wu J. Imaging of Adult Flatfoot: Correlation of Radiographic Measurements With MRI. American Journal of Roentgenology. 2015;204(2):354-359.

20. Richie D. Biomechanics and Clinical Analysis of the Adult Acquired Flatfoot. Clinics in Podiatric Medicine and Surgery. 2007;24(4):617-644.

21. Wacker J, Calder J, Engstrom C, Saxby T. MR Morphometry of Posterior Tibialis Muscle in Adult Acquired Flat Foot. Foot \& Ankle International. 2003;24(4):354-357.

22. Karasick $D$, Schweitzer $M$. Tear of the posterior tibial tendon causing asymmetric flatfoot: radiologic findings. American Journal of Roentgenology. 1993;161(6):1237-1240. 
23. Deland J, de Asla R, Sung I, Ernberg L, Potter H. Posterior Tibial Tendon Insufficiency: Which Ligaments are Involved?. Foot \& Ankle International. 2005;26(6):427-435.

24. Hastings $M$, Sinacore D, Mercer-Bolton N, McCormick J, Hildebolt C, Prior F et al. Precision of Foot Alignment Measures in Charcot Arthropathy. Foot \& Ankle International. 2011;32(9):867-872.

25. Nallamshetty L, Nazarian L, Schweitzer M, Morrison W, Parellada J, Articolo G et al. Evaluation of posterior tibial pathology: comparison of sonography and MR imaging. Skeletal Radiology. 2005;34(7):375-380.

\section{Tables}

Table 1. Type of sport, ultrasound and radiographic x-ray evaluation

\begin{tabular}{|c|c|c|c|c|c|c|}
\hline $\begin{array}{l}\text { Type of } \\
\text { sports }\end{array}$ & $\begin{array}{l}\text { Normal } \\
\text { ultrasound } \\
(\%)\end{array}$ & $\begin{array}{l}\text { Tenosyno } \\
\text { vitis } \\
(\%)\end{array}$ & $\begin{array}{l}\text { Tear } \\
(\%)\end{array}$ & $\begin{array}{l}\text { Normal } \\
\text { Radiograph } \\
\text { (\%) }\end{array}$ & $\begin{array}{l}\text { Flatfoot } \\
\text { (\%) }\end{array}$ & $N(\%)$ \\
\hline Athletics & $6(5,36 \%)$ & $8(7,1 \%)$ & $\begin{array}{l}1 \\
(0,9 \%)\end{array}$ & $5(4,5 \%)$ & $9(8 \%)$ & $14(12,5 \%)$ \\
\hline Wrestling & $10(8,9 \%)$ & $24(21,4 \%)$ & $\begin{array}{l}2 \\
(1,8 \%)\end{array}$ & $10(8,9 \%)$ & $24(21,4 \%)$ & $34(30.4 \%)$ \\
\hline Handball & $10(8,9 \%)$ & $10(8,9 \%)$ & $\begin{array}{l}1 \\
(0,9 \%)\end{array}$ & 7 (6,25\%) & $\begin{array}{l}13 \\
(11,65 \%)\end{array}$ & $20(17.8 \%)$ \\
\hline Fencing & $8(7,1 \%)$ & $18(16,1 \%)$ & $\begin{array}{l}2 \\
(1,8 \%)\end{array}$ & $4(3,6 \%)$ & $22(19,6 \%)$ & $26(23.2 \%)$ \\
\hline Wushu & $9(8,14 \%)$ & $5(4,5 \%)$ & $\begin{array}{l}1 \\
(0,9 \%)\end{array}$ & $7(6,25 \%)$ & $7(6,25 \%)$ & $14(12.5 \%)$ \\
\hline Gymnastics & $0(0 \%)$ & $4(3,6 \%)$ & $0(0 \%)$ & $0(0 \%)$ & $4(3,6 \%)$ & $4(3.6 \%)$ \\
\hline Total & $43(38.4 \%)$ & $69(61,6 \%)$ & $\begin{array}{l}7 \\
(6,3 \%)\end{array}$ & $33(29,5 \%)$ & $79(70,5 \%)$ & $112(100 \%)$ \\
\hline
\end{tabular}

Table 2. Ultrasounds of posterior tibial tendon 


\begin{tabular}{|llll|}
\hline Variables & N & Mean \pm SD & Median \\
\hline Hypoechoic fluid surrounding tendon & 112 & $2,57 \pm 1,6$ & 2,8 \\
\hline Tendon sheath size & 112 & $8,25 \pm 1,46$ & 8,2 \\
\hline Tendon Tear & 112 & $0,013 \pm 0,05$ & 0 \\
\hline Calcaneal inclination angle & 112 & $17,2 \pm 3,12$ & 16,6 \\
\hline
\end{tabular}

Table 3. Feiss line test and Calcaneal inclination from radiographic $x$-ray

\begin{tabular}{|lll|}
\hline Examination & Frequency & Percentage \% \\
\hline Feiss Line Test & & \\
\hline Normal & 12 & 10.7 \\
\hline $1^{\text {st }}$ degree & 75 & 67.0 \\
\hline $2^{\text {nd }}$ degree & 23 & 20.5 \\
$3^{\text {rd }}$ degree & 2 & 1.8 \\
Calcaneal Inclination(xray) & 33 & 29,5 \\
Normal & 79 & 70,5 \\
Flatfoot & & \\
\hline
\end{tabular}

Table 4. Correlation between the thickness of tendon sheath fluid, calcaneal inclination angle and feiss line test

\begin{tabular}{|lllll|}
\hline Variables & Mean \pm SD & Median & $\mathbf{p}$ & $\mathbf{r}$ \\
\hline Tendon sheath fluid & $8,25 \pm 1,6$ & 2,8 & $\mathbf{0 , 0 0 0}$ & $\mathbf{0 , 9 2 1}$ \\
\hline Calcaneal inclination angle & $17,2 \pm 3,1$ & 16,6 & & \\
\hline Feiss line test & & & $\mathbf{0 , 0 0 3}$ & $\mathbf{0 , 2 8 0}$ \\
\hline
\end{tabular}

Table 5. Correlation between the thickness of tendon sheath, calcaneal inclination angle and feiss line test 


\begin{tabular}{|lllll|}
\hline Variables & Mean \pm SD & Median & $\mathbf{p}$ & $\mathbf{r}$ \\
\hline Tendon sheath thickening & $8,25 \pm 1,45$ & 8,2 & $\mathbf{0 , 0 0 0}$ & $\mathbf{0 , 8 9 2}$ \\
\hline Calcaneal inclination angle & $17,2 \pm 3,1$ & 16,6 & & \\
\hline Feiss line test & & & $\mathbf{0 , 0 1 0}$ & $\mathbf{0 , 2 4 4}$ \\
\hline
\end{tabular}

Table 6. Correlation between the tendon tear gap, calcaneal inclination angle and feiss line test

\begin{tabular}{|lllll|}
\hline Variables & Mean \pm SD & Median & $p$ & $r$ \\
\cline { 1 - 4 } Tendon tear & $0,013 \pm 0,05$ & 0,00 & $\mathbf{0 , 7 2 8}$ & $\mathbf{0 , 0 3 3}$ \\
\cline { 1 - 4 } Calcaneal inclination angle & $17,2 \pm 3,1$ & 16,6 & & \\
\cline { 1 - 5 } Feiss line test & & & $\mathbf{0 , 5 4 1}$ & $\mathbf{0 , 0 5 8}$ \\
\hline
\end{tabular}

\section{Figures}

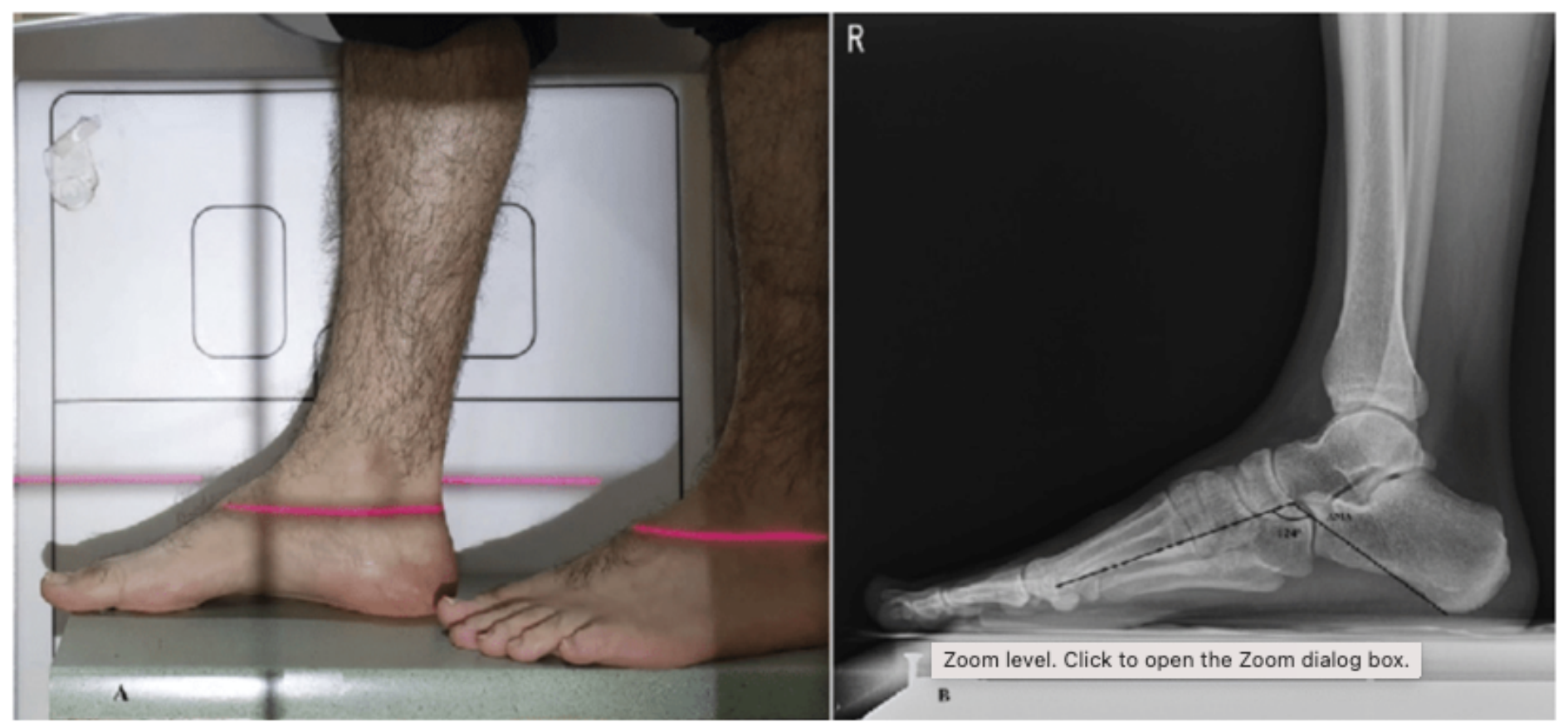

\section{Figure 1}

Positioning of lateral x-ray weight bearing foot (Belhan, O., Kaya, M. and Gurger, M., 2019) 


\section{Weight Bearing}

$\mathbf{R}$

\section{Figure 2}

Lateral radiograph shows the calcaneal inclination angle 


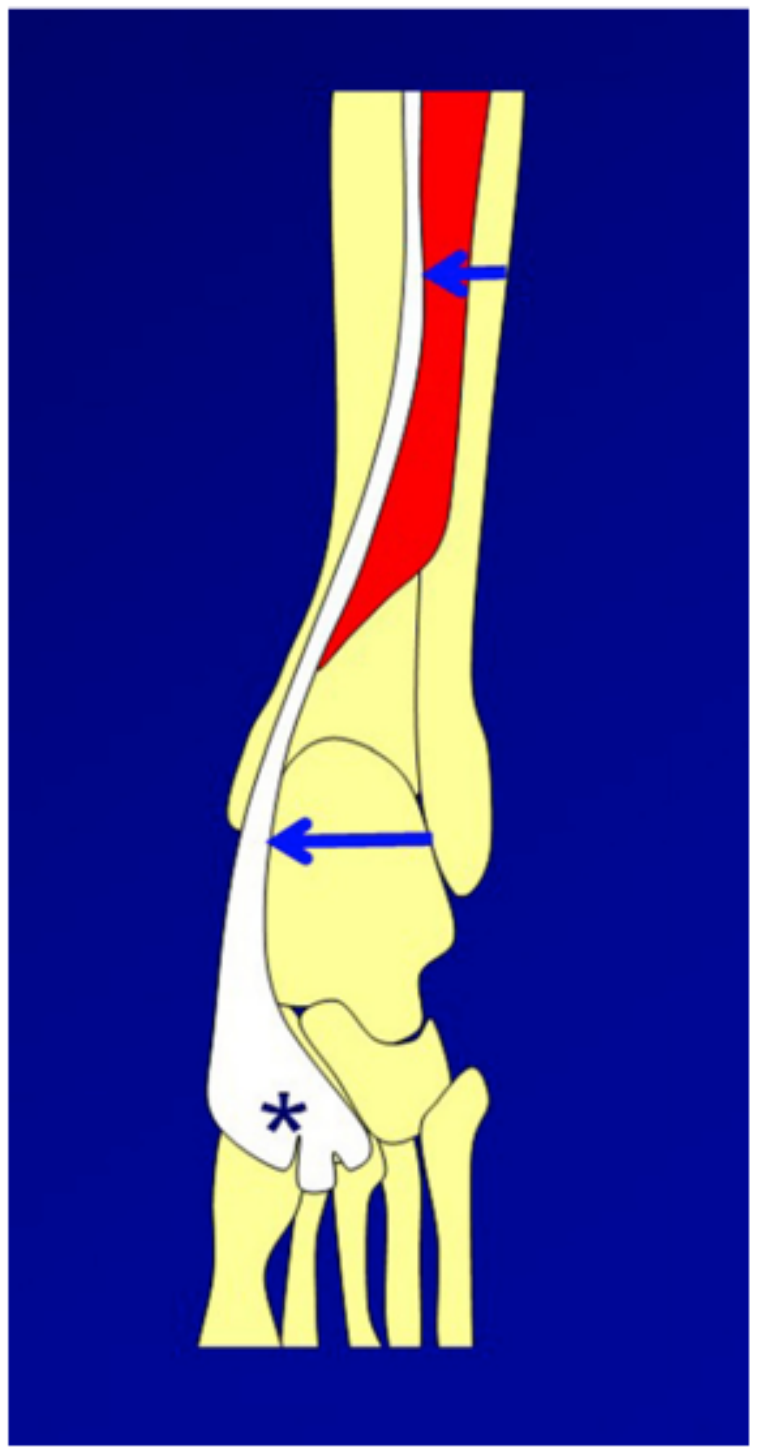

Figure 3

Schematic anatomy of tibial tendon. Medial malleolus (long arrow), sagittal lamina of the muscle (short arrow). Terminal portions fans out beneath navicular bone (asterisk) (Lhoste-Trouilloud, A., 2012.) 


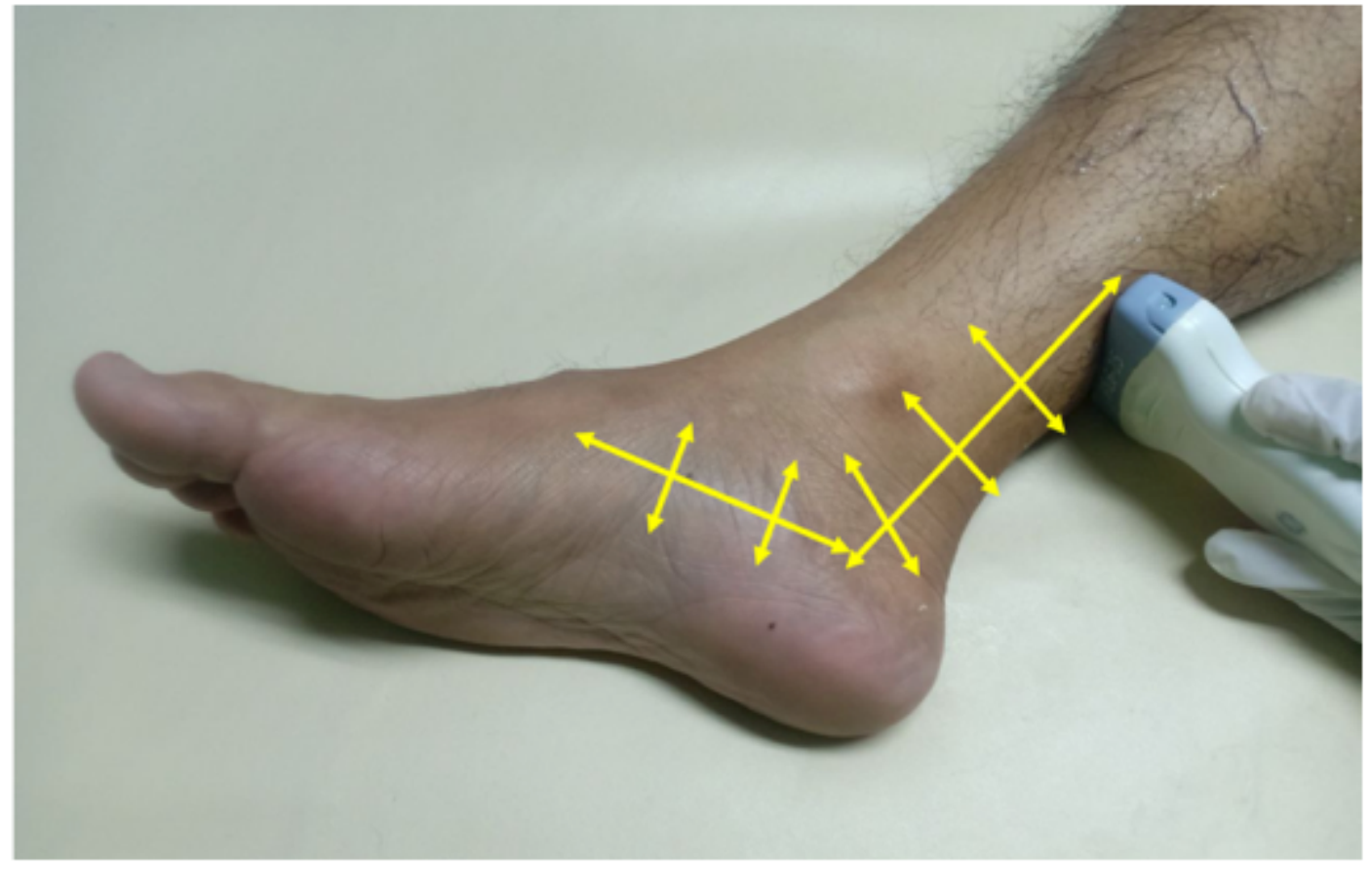

Figure 4

Transducer positioning for posterior tibial tendon ultrasound scanning

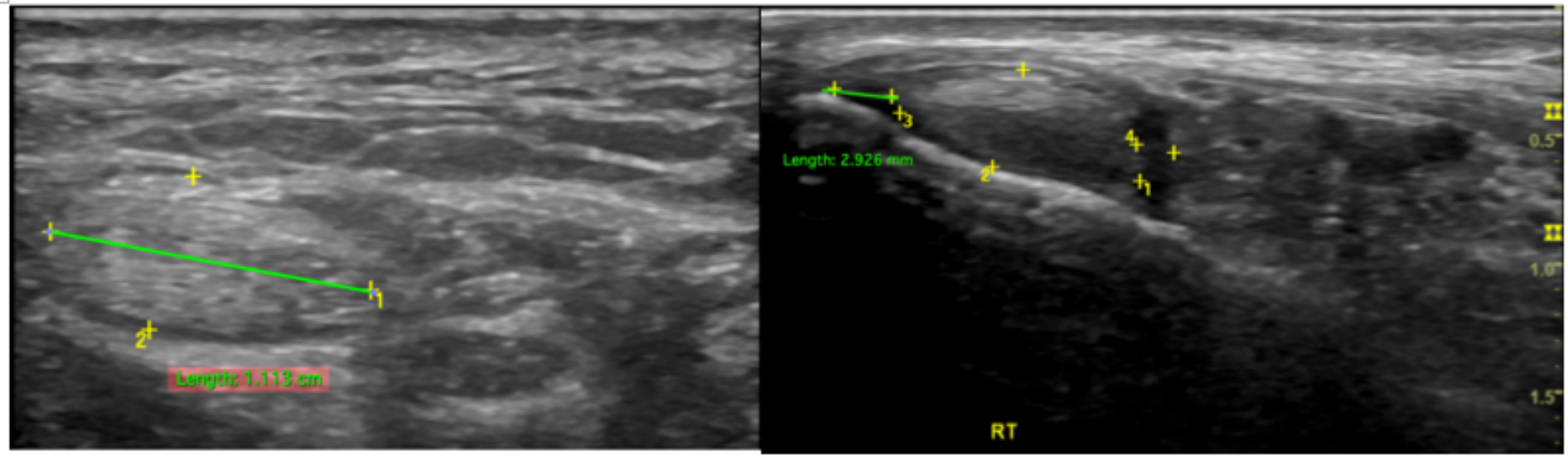

Figure 5

Transverse sonographic of posterior tibialis tendon with tenosynovitis showed thickening of the tendon fiber (A) with fluid in the tendon sheath (B) 


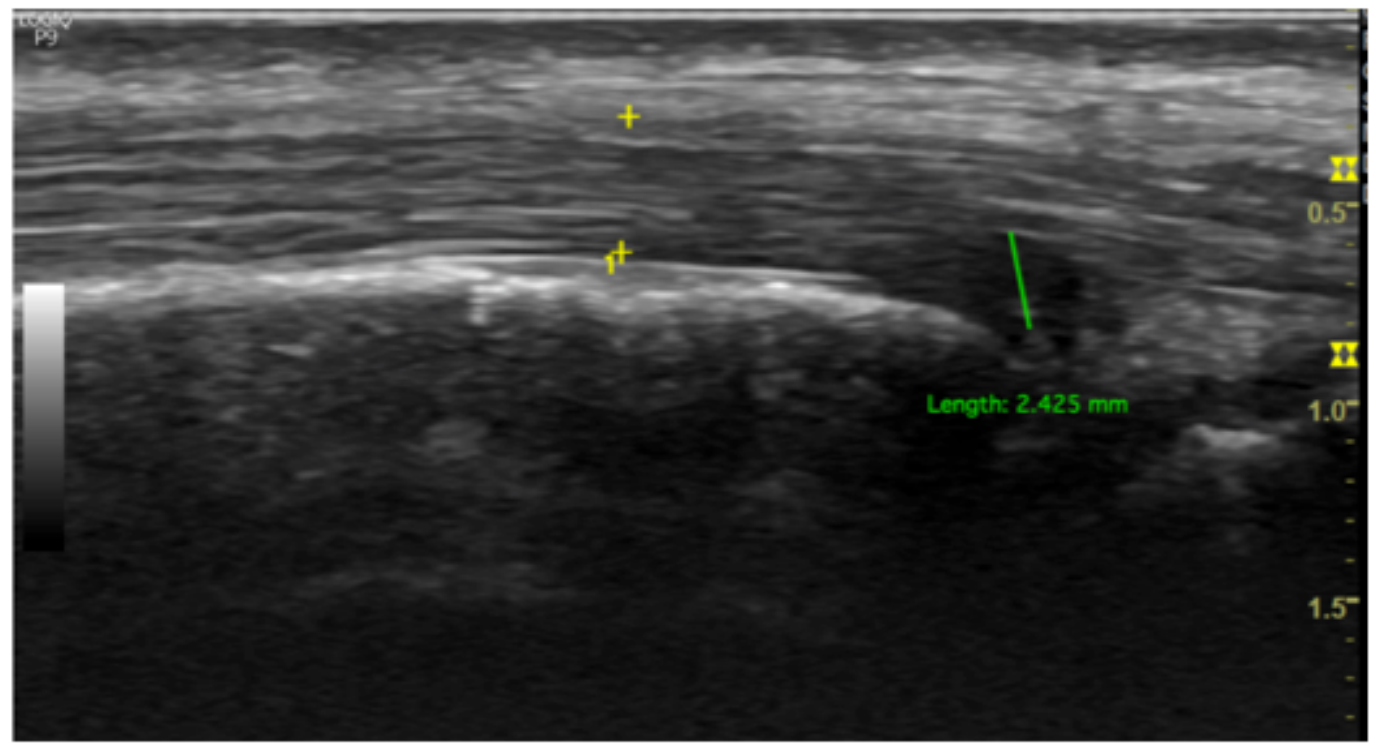

Figure 6

Longitudinal sonographic of posterior tibialis tendon with partial tear

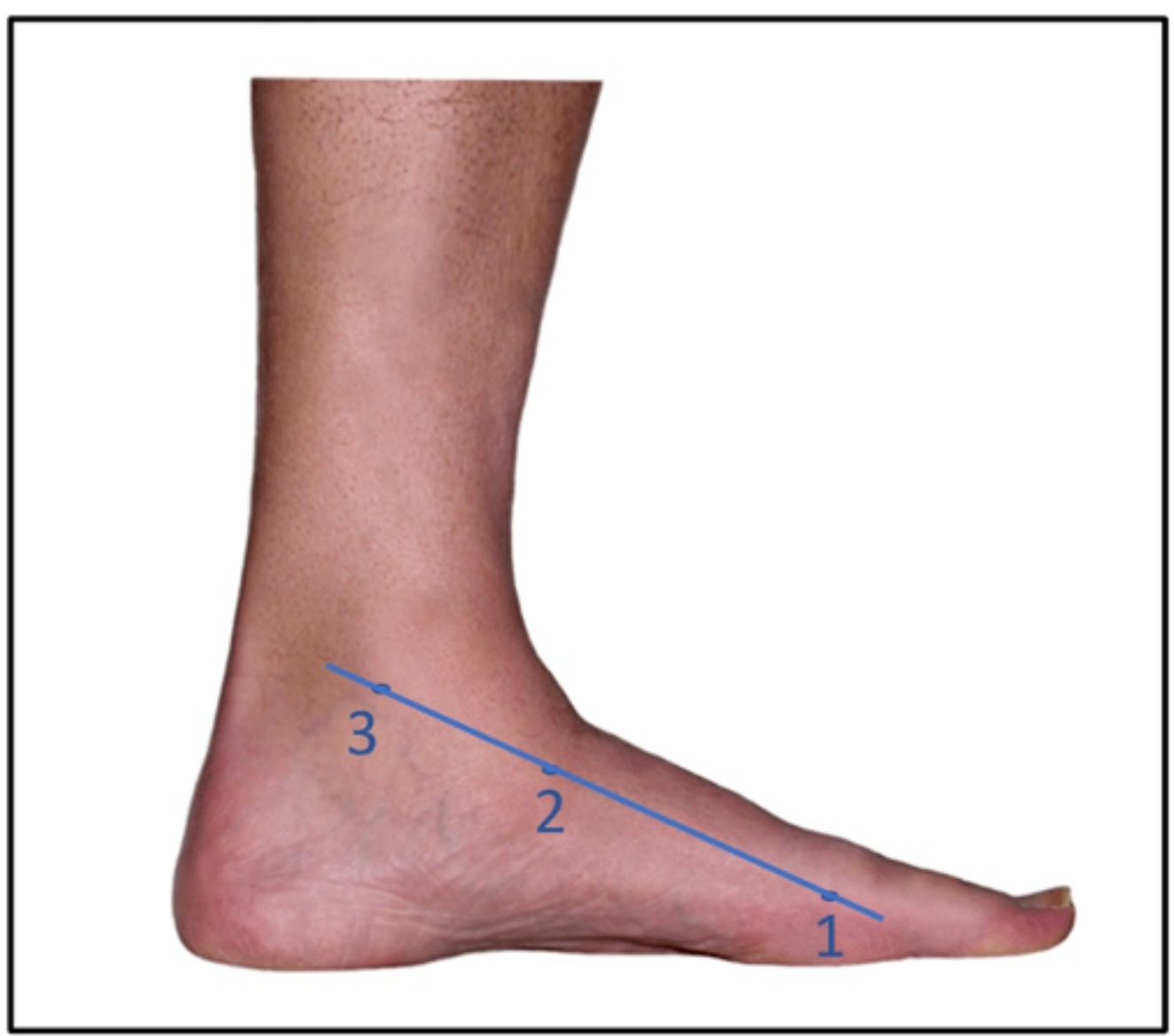

Figure 7 
Feiss Line in subtalar neutral position 1 head of first metatarsal bone; 2 navicular tuberosity; and 3 centre of the medial malleolus. 